\title{
MULHER E MATERNIDADE NO JORNAL ESCOLAR “O ESTUDANTE ORLEANENSE": UM OLHAR A PARTIR DA CONTRIBUIÇÃO DE SIMONE DE BEAUVOIR (SANTA CATARINA, 1949 - 1973)
}

Cintia Gonçalves Martins ${ }^{1}$

\section{INTRODUÇÃO}

No processo de implementação do Centro de Memória da Educação do Sul de Santa Catarina iniciado no ano de 2009, no qual tive a oportunidade de atuar como bolsista de Iniciação Científica do PIBIC/UNESC ${ }^{2}$, no período que era aluna de graduação do curso de História da Universidade do Extremo Sul Catarinense - UNESC, na etapa de coleta dos artefatos para compor o acervo digital do CEMESSC, foram identificados inúmeros documentos das Associações Auxiliares da Escola, sendo eles documentos da: Liga Pró Língua Nacional; Caixa Escolar; Cooperativa Escolar, Clube Agrícola; Pelotão de Saúde, Biblioteca Escolar; Jornais Escolares, Clube de Leitura, Liga da Bondade, Círculo de Pais e Professores, Orfeão Escolar, Museus Escolares e Centros de Interesses.

Entretanto, nos chamou a atenção entre os vários documentos encontrados da AAEs as Atas da Associação do Jornal Escolar, bem como inúmeros exemplares de Jornais Escolares de diferentes estabelecimentos de ensino. Pois, os documentos produzidos pelos/os estudantes são muito raros de serem encontrados nos acervos documentais das escolas, sendo eles os primeiros a serem descartados pelas instituições de ensino. De acordo com

\footnotetext{
${ }^{1}$ Graduada em História - Bacharel e licenciatura, pela Universidade do Extremo Sul Catarinense - UNESC. Especialista em Metodologia do Ensino de História - FACEL. Mestranda do Programa de Pós Graduação - Mestrado em Educação da UNESC, sob orientação da professora Dra. Giani Rabelo. Bolsista integral PROSUP/CAPES - UNESC. Aluna do Curso de Especialização em Gênero e Diversidade na Escola da Universidade Federal de Santa Catarina - Modalidade Semi Presencial. Membro do Grupo de Pesquisa História e Memória da Educação GRUPEHME/UNESC.cintiamartins@unesc.net

${ }^{2}$ Bolsista do Programa Institucional de Bolsas de Iniciação Cientifica - PIBIC/CNPq/UNESCda Pró - Reitoria de Pós - Graduaçã, Pesquisa e Extensão e Unidade Acadêmica de Humanas, ciência e educação UNESC. Projeto para a implantação do Centro de Memória da Educação do Sul de Santa Catarina -CEMESSC, etapas das escolas das microrregiões AMUREL e AMESC. Período de 01 de agosto de 2010 a 31 de Julho de 2011. .
} 
Amaral (2002) os impressos escolares produzidos por alunos/as, em muitas situações não chegam a ser considerados um documentos relevante para ser preservado, assim restando poucos exemplares nos acervos documentais das escolas.

Todavia, na coleta dos documentos do CEMESSC, deparamos com uma quantidade significativa de artefatos produzidos pelos/as educandos/as, Os Jornais Escolares. Nas escolas participantes do projeto, localizamos nos acervos escolares da Associação dos Municípios do Extremo Sul Catarinense - AMERC, na EEB. Jacinto Machado (Jacinto Machado): 1 exemplar e Ata das Reuniões da Associação do Jornal Escolar de 1964 a 1975; EEB Manoel Gomes Baltazar (Maracajá) 22 exemplares de 1950 a 1970. E da Associação dos Municípios da Região de Laguna - AMUREL o educandário, EEB. Professora Eulina Heleodoro Barreto (Imaruí) Ata das Reuniões de Associação do Jornal Escolar de 1966 a 1967. Na Associação dos Municípios do Extremo Sul Catarinense - AMESC, na escola EEB. Costa Carneiro (Orleans): 57 exemplares e Ata das Reuniões da Associação do Jornal Escolar de 1949 a 1972; EEB. Udo Deeke (Treviso): Ata das Reuniões de Associação do Jornal Escolar de 1938/1940 a 1948; EEB. Salete Scott dos Santos (Içara): Ata das Reuniões de Associação do Jornal Escolar de 1956 a 1970; EEB. Prof. Lapagesse (Criciúma: Ata das Reuniões de Associação do Jornal Escolar 1963 a 1969; EEB. Padre Schuller (Cocal do Sul)1 exemplar do Jornal Escolar de 1984 a1985; EEB. José do Patrocínio (Siderópolis) 5 exemplares do Jornal Escolar 1984 a 1986.

Entre os educandários apresentados acima o que mais chamou nossa atenção foi a Escola de Educação Básica Costa Carneiro, pela quantidade significativa de Jornais salvaguardo em seu acervo documental. Ao todo foram identificados cinquenta e sete (57) exemplares do Jornal Escolar O Estudante Orlenanse ${ }^{3}$ juntamente com uma Ata de Reunião que registra os eventos, as eleições entre outras demandas da Associação do Jornal Escolar entre os anos de 1949 a 1972.

${ }^{3}$ O jornal Escolar "Estudante Orlenanse" sofreu variações quanto à sua denominação. Aparecem nos exemplares analisados as seguintes nomenclaturas: "O Estudante", "O Estudante Orleanês", entretanto a maioria dos Jornais consta a nomenclatura o "O Estudante Orleanense". 
Com o ingresso no mestrado em Março de 2015, sob orientação da professora Dra. Giani Rabelo, iniciei uma investigação, que elegeu como lócus de pesquisa o Jornal Escolar o "Estudante Orlenanse". Pois, esse artefato suscitou muitos questionamentos a cerca de sua preservação por parte do educandário e da grande quantidade de exemplares encontrada.

Os Jornais Escolares são documentos redigidos pelo/as educandos/as a partir de práticas escriturais que levaram a produção de um suporte material que contribuíram para modificar a cultura escolar dos estabelecimentos de ensino brasileiros. No estado de Santa Catarina essa práxis foi incorporada nos educandários nos primórdios do século $\mathrm{XX}$, a partir da criação das AAes nas instituições de ensino.

Com a proclamação oficial da República em 15 de Novembro de 1889, o governo buscou por intermédio da educação, criar uma identidade nacional brasileira, bem como civilizar e modernizar a nação que estava constituindo-se. Esse processo tornou-se ainda mais relevante na década de 1930, no Governo de Getúlio Vargas (1930 - 1945). Nesse sentindo, ao longo da primeira metade do século $\mathrm{XX}$, foram construídas novas instituições escolares, formação profissional de educadores/as, compras de materiais pedagógicos que pudessem contribuir para modificar os métodos de ensino e a aprendizagem, do mesmo modo que, foram decretadas diversas leis que buscavam criar uma educação homogenia para os todos os estados brasileiros.

Entre essas medidas estava à criação das Associações Auxiliares da Escola, que se baseavam no modelo educacional dos intelectuais da Escola Nova, difundida com o manifesto dos Pioneiros publicado 1932, assinado por vários estudiosos da educação ${ }^{4}$ da época. Os escolonovistas possuíam uma perspectiva educacional que se colocava em oposição aos métodos de ensino da escola tradicional ${ }^{5}$, baseado no modelo educacional Norte Americano dos professores John Dewey e Willian Kilpatrick. Os intelectuais idealizavam método de educação, pautados principalmente em um modelo pedagógico, no

\footnotetext{
${ }^{4} \mathrm{O}$ manifesto da escola nova foi assinado por vinte e seis (26) intelectuais brasileiros, entre eles Fernando Azevedo, Anísio Teixeira, Cecília Meirelles, entre outros.

${ }^{5}$ Segundo Saviani (2009, p. 10), o papel da pedagogia tradicional é difundir a instrução, transmitir os conhecimentos acumulados pela humanidade e sistematizados logicamente. $O$ mestre-escola será o artífice dessa grande obra. A escola se organiza, pois como uma agência centrada no professor, o qual transmite segundo uma gradação lógica, o acervo cultural aos alunos. A estes cabe assimilar os conhecimentos que lhes são transmitidos.
} 
qual os educandos/as eram considerados/as o centro no processo educacional e não mais os/as professores/as, como era no modelo de escola tradicional. Neste sentido, valorizava-se o papel da criança no seu processo de ensino e aprendizagem e o/a professor/a seria o/a mediador/a.

Com as transformações sociais ocorridas na sociedade brasileira, com o processo de implantação do modelo capitalista de produção, urbanização e individualismo social a escola tinha o papel de preparar as crianças para o trabalho, pois serão elas/es o futuro adulto que servirá de mão de obra para o modelo capitalista de sociedade. Assim sendo, a escola tradicional com seus métodos pedagógicos não conseguiria atingir as capacidades e aptidões das/os alunas/os, apenas uma escola nova com métodos didáticos diferenciados, materiais pedagógicos, espaços físicos amplos, possibilitariam o desenvolvimento individual das capacidades e das aptidões das educandas/os.

No estado catarinense, as práticas de educação da Escola Nova apareceram oficialmente no decreto Estadual n. 2.991 de 28 de abril de 1944, do interventor federal Nereu Ramos (1937 - 1945). Trata-se, portanto, da legislação que regulamenta oficialmente a aplicação das Associações Auxiliares da Escola - AAE, que deveriam ser regulamentadas conforme consta na lei, nas instituições escolares das redes estaduais, municipais e privadas do Estado de Santa Catarina.

As Associações Auxiliares da Escola constituem em organizações estudantis, formada por educandos/os da mesma instituição escolar de diferentes séries ou da mesma classe escolar, sendo que as atividades são coordenadas por um/a educador/a responsável que organiza as tarefas determinadas para cada associação. As associações têm como função o mecanismo de auxiliar as atividades de ensino, bem como contribuir para a socialização, moralização e civilização dos/as alunos/as, com a intenção de aproximar a família do meio escolar. (PETRY, 2013)

Entre as AAEs, encontra-se a Associação do Jornal Escolar, uma agregação de estudantes, formada por um ditetor/a, gerentes, repórteres/as e secretários/as escolhidos/as por meio de eleições. Tal associação era organizada por uma professora orientadora que vigiava os afazeres dos/as estudantes. A associação do Jornal Escolar tinha por objetivo o trabalho em 
equipe que registrava os acontecimentos, as vivencias, as experiências dentro e fora do ambiente escolar, bem como, materializaram por meio dos textos e imagens expostos nos impressos as intenções políticas, religiosas e sociais de determinadas instituições em seu tempo e espaço. Os/as educandos/as que faziam parte da associação do Jornal Escolar eram responsáveis por sua distribuição, tanto dentro do educandário, como para os familiares, assim contribuindo para a proximidade entre família e escola.

Nesse sentindo os Jornais Escolares trazem em sua materialidade componente diversos para compreendemos as múltiplas culturas escolares que se manifestou nas escolas do estado de Santa Catarina, bem como, analisarmos as representações de gênero que eram difundidas nas páginas do Jornal Escolar o "Estudante Orlenanse".

\section{METODOLOGIA}

Para conseguir compreender as representações gênero que foram difundidas nas páginas do Jornal Escolar, o estudo tinha como principal objetivo analisar o conteúdo do impresso escolar "O Estudante Orleananse", buscando identificar as representações de gênero que foram veiculadas nos textos e imagens, a fim de dar visibilidade às representações do feminino, com a intenção de identificar os estereótipos que contribuem para as desigualdades de gênero no universo escolar.

Inicialmente, a análise dos referidos documentos foi pautada pelas seguintes questões: Quais representações de feminino e masculino permeiam os impressos escolares? Que prescrições de masculino e feminino foram disseminadas? Como se deu a participação de meninos e meninas na elaboração dos Jornais na condição de autores/autoras dos conteúdos divulgados? Quais os temas veiculados nos jornais que eram atribuídos às meninas/mulheres?

Para dar as respostas para essas questões iniciei o processo de analise dos impressos estudantis, desse modo, a pesquisa aqui apresentada é do tipo documental com analise de conteúdo, de abordagem qualitativa, descritiva e exploratória. 
Entendendo segundo Damaceno (2009, p. 455) que "[...] o método de pesquisa documental [é] aquele que busca compreendê-la [a realidade] de forma indireta por meio da análise dos inúmeros tipos de documentos produzidos pelo homem". Os documentos são aqui compreendidos, como quaisquer objetos, qualquer base de conhecimento fixada materialmente que elucide, instruam, reconstrua, prove ou comprove cientificamente algum fato ou acontecimento.

A fim de desenvolver este estudo iniciou-se um processo de análise do conteúdo dos jornais, atas e legislações. Os Jornais Escolares "O Estudante Orleanense" encontram-se digitalizados e disponibilizados virtualmente na base de dados do CEMESSC. Na análise foi construída uma tabela, utilizando a ferramenta do Microsoft Excel, da qual pude retirar e registrar os dados necessários sobre os Jornais Escolares.

A tabela contém os seguintes itens de análise: Ano e Mês; Diretor/a; Gerente; Secretários/as; Repórteres/Autores/as; Descrição do suporte: Dimensões, número de páginas, número de ilustrações, Técnica de impressão, Quantidade de Sessões/colunas, Títulos/Tema dos registros/Ator/a/Série-ano/; Cópia ou Texto Livre - Gênero literário; Descrição das Imagens; Textos/ilustrações/registros que trazem representações de Gênero Observações; Patrocinadores; Observações da Ata. Está coleta de dados possibilitou um entendimento mais amplo dos conteúdos que constam nos impressos.

A ata de reuniões da Associação do Jornal Escolar, datada de 1949 a 1986, também foi lida e analisa, além da legislação educacional, em nível federal e estadual, das décadas de 1940 e 1960, sobre as Associações Auxiliares da Escola, que enfatizavam a implantação e regulamentação do Jornal Escolar nas escolas brasileiras.

\section{RESULTADOS E DISCUSSÃO}

Ao concluir a análise de conteúdo nos Jornais Escolares "O Estudante Orlenanse", averiguei que as desigualdades de gênero estão presentes nos conteúdos que compõem os impressos. As disparidades estão 
apresentadas na composição da diretoria, na escolha dos reportares, das secretarias, do gerente, isto é, encontrando-se até mesmo, nos textos escolhidos e redigidos para compor o enredo. Entendi-se que as relações de gênero permeiam a construção do impresso escolar e sua trajetória dentro do educandário. Todavia, o que mais despertou nosso interesse, foi a forma como as mulheres são representadas nos textos e imagens do Jornal Escolar. As representações do feminino estão, em sua maioria, relacionadas às questões da maternidade, ou seja, da mulher como mãe. As mulheres são descritas ou representadas no impresso estudantil apenas no mês de Maio, data emblemática que se comemora o dia das mães, bem como em textos que as apresentam como mães, destinando às meninas/mulheres o papel da maternidade, naturalizada pelo viés biológico. As representações são carregadas de prescrições de como ser mãe, o que é ser mãe, como uma mãe deve comportar-se perante a sociedade.

Em função da grande incidência de conteúdos que reforçavam ideia de que o principal papel da mulher é ser mãe, principalmente nos textos referentes ao "Dia das Mães", houve um realinhamento do objetivo central, ou seja, busca-se compreender as representações de mulher/maternidade que foram disseminadas no Jornal Escolar "O Estudante Orleanense nos textos comemorativos ao "Dia das Mães", entre as décadas 1950 a 1970.

Para dar conta desta nova problemática foram agregadas outras questões norteadoras: Como a maternidade é veiculada no Jornal escolar? Que argumentos são utilizados para definir/descrever maternidade? Como os escritos de Simone de Beauvoir sobre a condição feminina contribuem para a análise da maternidade nos Jornais Escolares "O Estudante Orleanense?"

Assim sendo, busco perceber como o Jornal Escolar "O estudante Orleananse disseminou a representação de maternidade e de mulher/mulheres, utilizando do suporte teórico de Scott (1995), Pinsky (2003), Pedro (2003; 2005), Graupe (2009) e Louro (1997) para compreender o conceito de Gênero, história das mulheres e representação feminina. Para problematizar as questões relacionadas à maternidade, busca-se compreender como os escritos da filosofa existencialista Simone de Beauvoir sobre a condição feminina, na obra O Segundo Sexo, volume um (1) "Fatos e Mitos" e o volume dois (2) "A Experiência Vivida", contribuem compreender a condição 
feminina e destino materno, difundido nas páginas do Jornal Escolar "O Estudante Orleanense".

\section{CONCLUSÃO}

A pesquisa encontra-se em andamento, as considerações finais são temporárias, podendo ocorrer alterações até o final do estudo. Entretanto, ao realizar uma analisasse inicial de alguns dos textos publicados no Jornal Escola, nota-se como o Jornal Escolar O Estudante "Orleananse" está permeado pelas questões de gênero. Especialmente, no que se refere à representação de um ideal de mulher/mulheres, que se encontra vinculada à maternidade, observa-se nos textos, a construção da mãe amorosa, cuidadosa, da qual abdica de sua vida pública para dedicar-se à vida privada, ou seja, ao lar e ao cuidado das/os filhas/os, ocultando as dificuldades da maternidade e a naturalização biológica deste processo, reforçando a ideia de que ser mãe é a função social mais importante das mulheres e ao mesmo tempo é destino.

\section{REFERÊNCIAS}

AMARAL, Giana Lange do. Os impressos estudantis em investigações da cultura escolar nas pesquisas histórico-institucionais. História da Educação, ASPHE/UFPel,n. 11, p. 117- 130, abr. 2002.

BEAUVOIR, Simone. O segundo sexo: volume único. Tradução Sérgio Milliet. 2. Ed. Rio de Janeiro: Nova Fronteira, 2009.

CENTRO DE MEMÓRIA DA EDUCAÇÃO DO SUL DE SANTA CATARINA. CEMESSC. Disponível em: < http://www.bib.unesc.net/muesc/muni_07.php. > Acesso em: 02 mar.2015.

DAMACENO, Ana Danoella et alt. Pesquisa Documental: alternativas investigativas na formação docente. In: IX congresso nacional de educação EDUCERE e III encontro Sul brasileiro de Psicopedagogia, 2009, Curitiba: Champagnat, 2009, p. 4556-4566. Disponível em: <http://www.pucpr.br/eventos/educere/educere2009/anais/pdf/3124_1712.pdf> Acesso em: 24 Jun.2016.

FREINET, Célestin. O Jornal Escolar. Lisboa, Editorial Estampa, 1974. 
GRAUPE. Mareli Eliane. Gênero e Magistério: Discursos e práticas sociais. Ed.Usina de Letras. Brasília - DF 2009.

LOURO, Guacira Lopes. Gênero, sexualidade educação: uma perspectiva pós estruturalista. Petrópolis, RJ: Vozes, 1997.

PEDRO, Joana Maria. Traduzindo o debate: o uso da categoria gênero na pesquisa histórica. História, São Paulo, v.24, n.1, p.77- 98, 2005. Disponível em: < http://www.scielo.br/pdf/his/v24n1/a04v2 4n1>. Acesso em: 10 Ago 2015.

PETRY, Marilia Gabriela. Da recolha à exposição: a constituição de museus escolares em escolas públicas primárias de Santa Catarina (Brasil - 1911 a 1952). 2013. 224 f. Dissertação (Mestrado em educação) - Universidade do estado de Santa Catarina, Florianópolis.

PINSKY, Carla Bassanezi; PEDRO, Joana Maria. Mulheres: igualdade e especificidade. In: PINSKY, Jaime; PINSKY, Carla Bassanezi (orgs.). História da cidadania. São Paulo: Contexto, 2003. p.265-309.

SANTA CATARINA. Decreto n. 2.991, de 28 de abril de 1944. Aprova as instruções para as associações auxiliares da escola nos estabelecimentos de ensino estaduais, municipais e particulares. Florianópolis: Imprensa oficial do Estado, 1944.

SAVIANI, Dermeval. Escola e democracia. 20 ed. São Paulo: Ed. Cortez, 1988.

SCOTT, Joan. Gênero: uma categoria útil de análise histórica. Educação e realidade. Porto Alegre, v. 20, 2, p. 71-99, jul/dez, 1995. 